\title{
La deuda: del sueño a la pesadilla colectiva. Endeudamiento de mujeres rurales del centro de Veracruz
}

\author{
Gabriela Guzmán Gómez
}

\begin{abstract}
La entrada masiva de microcréditos en las áreas rurales del centro de Veracruz ha desencadenado una tendencia al sobreendeudamiento de las mujeres. Entre las causas que generan este proceso están la vulnerabilidad que vive la población rural y las metodologías de trabajo que priorizan la rentabilidad a costa de la adecuación de los servicios a las necesidades y posibilidades de este sector de la población. El proceso de sobreendeudamiento rebasa el incumplimiento de un compromiso adquirido: implica la relación entre la microfinanciera, la deudora y los actores involucrados, y conlleva costos personales, económicos y sociales con consecuencias presentes y futuras para los grupos domésticos y sus comunidades.
\end{abstract}

PALABRAS CLAVE: endeudamiento, vulnerabilidad, microfinanzas, microfinancieras, mujeres rurales

\section{Debt: from the Dream to the Collective Nightmare. Indebtedness of Rural Women in the Centre of Veracruz}

The massive entry of microcredit in the rural areas of the central region of Veracruz has triggered a trend to women's debt overhang. Among the causes that generate this process are the vulnerability of such population and the working methodologies of commercial microfinancial companies that prioritize profitability instead of adequate services for the specific needs and possibilities of rural population. The process of overhang debt exceeds the breach of a commitment: it involves the relationship among the microfinance, the debtor and other actors. Furthermore, it has personal, economic and social costs with several consequences for the present and future for the domestic groups and their communities.

KEYWORDS: indebtedness, vulnerability, microfinances, microfinances institutions, rural women

Gabriela Guzmán Gómez: Cooperativa de Mujeres Cafetaleras Independientes,

Coatepec, Veracruz, México

gabguz2002@yahoo.com.mx

Desacatos, núm. 44, enero-abril 2014, pp. 67-82

Recepción: 23 de abril de 2012 / Aceptación: 3 de septiembre de 2013 


\section{INTRODUCCIÓN}

$\mathrm{T}$ iene escasos 11 años que ingresaron las microfinancieras comerciales a las comunidades rurales del centro del estado de Veracruz con la oferta masiva de microcréditos a mujeres. En pocos años la oferta y la demanda de estos créditos se han incrementado y la población ha incorporado los préstamos a sus estrategias de supervivencia. Una de las consecuencias de la sobrevaloración de los créditos en la dinámica económica familiar es el aumento del endeudamiento de la población. En este artículo se analiza el proceso de endeudamiento que se presenta en esta región con base en la experiencia de las socias de una caja de ahorro: la Cooperativa de Mujeres Cafetaleras Independientes (Comucafi). Las microfinancieras comerciales a las que hago referencia que operan en esta zona son Compartamos y Finamigo. La información de campo proviene de la colaboración que he establecido con la Cooperativa durante más de diez años y de consecuencias personales, familiares y comunitarias que conlleva realizar o no el pago. En los siguientes apartados analizo las causas que desencadenan el sobreendeudamiento: la vulnerabilidad de la población rural y las condiciones que imponen las microfinancieras comerciales para otorgar los microcréditos. Asimismo expongo los costos económicos, personales y sociales derivados de la dificultad de los usuarios para pagar el o los créditos comprometidos y, de manera sucinta, cómo las redes sociales amortiguan las consecuencias de este proceso.

\section{SERVICIOS FINANCIEROS Y DESARROLLO}

Desde hace muchos años se ha evidenciado el potencial de los servicios financieros para generar desarrollo. En el caso de las mujeres rurales la propuesta de microcréditos con pequeños pagos que inició en Bangladesh ha representado, para muy diversos sectores, una esperanza para disminuir la pobreza en el mundo (Cumbre de Microcrédito, 2013). El ahorro asociado con el crédito tiene el potencial de fortalecer los proyectos o actividades económicas, sociales y/o familiares de la población de escasos recursos y asimismo producir beneficios individuales y familiares e incluso incidir en la mejora de la colonia, el barrio, la comunidad o la región. Si bien el potencial del ahorro en el desarrollo es muy importante (Castillo, 2012), las microfinancieras no lo aprovechan o no lo utilizan, entre otras razones por las leyes que lo regulan y los costos que implica cumplirlas. No profundizaré en el ahorro porque no está asociado con el sobreendeudamiento. Respecto de los créditos, su potencial en el desarrollo está muy acotado. Autores como Dichter (2007), ferviente defensor del microcrédito, en los últimos años ha matizado su posición frente a este servicio. En el mismo sentido y en relación con la pobreza, Naila Kabeer considera que los microcréditos: 
no pueden sustituir políticas más amplias que promuevan un crecimiento económico en favor de los más necesitados, un desarrollo social equitativo y una participación democrática en foros colectivos de toma de decisiones. En la ausencia de dichas políticas, las microfinanzas pueden, en el mejor de los casos, proporcionar una red de seguridad para los pobres, más que una escalera para salir de la pobreza (Kabeer, 2012: 66).

Esta autora plantea que el potencial del microcrédito en el empoderamiento de las mujeres depende de los siguientes factores:

la filosofía que rige su entrega, el grado en el que se adapten a las necesidades e intereses de aquellos a los que se busca llegar, la naturaleza de las relaciones que rigen su entrega y, el dato más elusivo en los estudios del desarrollo, el calibre y compromiso de las personas responsables de la entrega. El diseño de los servicios financieros para los pobres debe basarse en una comprensión sobre bases empíricas de la relación entre contexto, enfoque e impacto (Kabeer, 2012: 44).

Un producto crediticio necesita estar adaptado a las necesidades, posibilidades y expectativas de los usuarios, y los prestatarios requieren contar con proyectos bien planteados, con respaldo técnico-administrativo, acordes al contexto local para implementar el proyecto y para resolver problemas que se presenten, además de un mercado asegurado. No todos los productos crediticios ni las usuarias de estos servicios cuentan con estas condiciones cuando solicitan e invierten un crédito en sus negocios o en sus viviendas. Sin embargo, los créditos se solicitan y se invierten y no todas las experiencias resultan exitosas.

En los últimos años se presenta un serio problema de endeudamiento asociado a la metodología de trabajo de las microfinancieras comerciales, a la permanente crisis del medio rural, a la vulnerabilidad de la población y a la falta de herramientas de las personas para elegir el servicio financiero adecuado para responder a sus necesidades y a sus posibilidades. Con el fin de facilitar el análisis y tomando en cuenta que existe una enorme gama de instituciones que ofrecen servicios financieros, las agrupo en dos grandes conjuntos: por una parte, las cajas de ahorro y, por otro, las microfinancieras comerciales. Las cajas de ahorro generalmente practican las microfinanzas sociales y proporcionan servicios de ahorro y de crédito. Una de las preocupaciones de estas organizaciones es asegurar que los servicios que ofrecen estén adaptados a las necesidades, posibilidades y expectativas de los(as) usuarios(as), por lo que los servicios financieros van acompañados por procesos educativos y se enmarcan dentro de proyectos de desarrollo social. Dentro de las microfinancieras comerciales integro a las entidades cuya finalidad es el lucro y se circunscriben a ofertar masivamente microcréditos con características homogéneas sin considerar las particularidades de la población ni de la región.

\section{LAS SOCIAS DE LA COMUCAFI Y LOS SERVICIOS FINANCIEROS}

En la región central de Veracruz hace escasos 11 años que las mujeres rurales tienen acceso a servicios financieros. La Comucafi está integrada por mujeres rurales que utilizan los servicios de ahorro y crédito desde hace diez años y donde se prioriza el ahorro sobre el crédito. Como en la mayor parte del país, los grupos domésticos de las socias han sido impactados por las diversas crisis y viven bajo condiciones económicas difíciles. Combinan actividades agropecuarias, coordinadas por los esposos, con el trabajo asalariado y con otras actividades comerciales de iniciativa propia. En los comienzos de la Cooperativa, las socias tenían sentimientos encontrados en relación con los créditos. Por un lado albergaban la ilusión de disponer de recursos adicionales al precario presupuesto familiar y el anhelo de iniciar una actividad productiva, en tanto que por otro lado también sentían vergüenza de exponer sus carencias frente a un colectivo y temor de no tener la capacidad de pagar el crédito. 
A diez años de distancia las socias de la Cooperativa han asumido el ahorro y el crédito como parte de la dinámica familiar, lo que repercute en su vida desde diversos ángulos. Las mujeres han logrado consolidar sus negocios, han resuelto problemas de salud, se han incorporado a la toma de decisiones en la familia, han mejorado sus viviendas, se han dado cuenta de que tienen capacidad de soñar y de hacer realidad sus sueños, han disminuido su tensión gracias a que cuentan con un fondo de ahorro, han fortalecido su autonomía y/o han disminuido la dependencia hacia sus maridos, etc. Actualmente muchas mujeres han integrado el ahorro y los créditos en sus estrategias de reproducción y han encontrado la forma de sacarles provecho o, al menos, de no salir perjudicadas en su manejo. Hay quienes han desarrollado capacidades para manejar varios créditos con diferentes instituciones. Estas mujeres combinan de manera muy precisa las ventajas y condiciones de cada institución y las adecuan a las necesidades y a los recursos con los que cuenta el grupo doméstico.

Un ejemplo es la familia Álvarez, que tiene ingresos provenientes de seis actividades productivas y de un programa de gobierno: además de producir café, el esposo compone electrodomésticos, tiene varias "maquinitas" y vende plátanos en varias comunidades. Irma, la esposa, tiene una pequeña papelería, un molino de nixtamal y recibe cada dos meses recursos del Programa Oportunidades. Los Álvarez utilizan los servicios de dos cajas de ahorro para apuntalar las actividades productivas y asegurar la reproducción de su grupo doméstico. Manejan de manera coordinada estos servicios:

Comucafi es esencial, yo veo cómo lo pago, vendo otra cosa, vuelvo a pedir [...]. Ahí lo vamos jineteando, revolviendo. A mí los préstamos me solucionan la vida en ese momento, después la pensamos de cómo pagar [...]. También estamos en la Caja de Teocelo, es una ayuda, pido acá y luego voy y pido allá y cuando llega el café, ya a pagar, a pagar [...]. Yo trato de ahorrar en ésta y de ahorrar allá [...]. Lo que voy sacando a la semana voy ahorrando y voy pagando, luego viene la cosecha y pagamos y a guardar [...]. Nunca tenemos dinero propio, siempre es prestado (entrevista a Irma Álvarez, 2008).

Cada vez son más familias las que han desarrollado capacidades para aprovechar los servicios financieros. Sin embargo, un porcentaje considerable de mujeres ha vivido al menos una experiencia difícil al no poder cumplir con sus compromisos como lo planearon inicialmente. Una de las causas más visibles de este fenómeno es el uso de créditos simultáneos. Un ejemplo es Crista, quien solicita de manera frecuente créditos a diversas instituciones:

Yo he estado mucho en créditos, más para los cuartos. Un crédito, saqué unos muebles [...] en diciembre fue el colado 150 metros y en marzo los XV años de mi hija. Sí, yo me endrogué, pero sí, también no debo muchisísimo. Yo debo 50000 pesos, le debo al señor de material y también debo en un crédito que es del Familiar [Crédito Familiar]. De mis drogas él no sabe. Yo tampoco le pido para pagar. Si me endrogo es para sacar a los hijos adelante, para tener una casa (entrevista a Crista, 2010).

Así como Crista, cada vez más mujeres buscan resolver sus dificultades económicas a través de la sobreoferta de créditos. Esta situación está provocando un serio problema de sobreendeudamiento en la región, mismo que la Cooperativa ha enfrentado de diversas maneras. Por una parte, pretende entender las causas y establecer condiciones especiales para quienes tienen complicaciones de salud, maritales, de desempleo o cuando se cae el precio de los productos agropecuarios. Por otra parte, se promueve la educación financiera, cuyo principal elemento es el fomento del ahorro sobre el crédito y la transparencia que conlleva explicar las implicaciones de contratar un crédito. Asimismo, el reglamento elaborado colectivamente por las socias estipula restricciones para aquellas que se retrasaron en sus pagos y alerta a las mujeres de los riesgos que implican los créditos ante la crisis económica. Comucafi, como otras cajas de ahorro, recurre a su vez a la presión 
social y abre espacios de negociación dialogada. En última instancia está la vía legal que se ejerce a partir de los valores y principios éticos y cuida siempre de no pasar por encima de la dignidad de las socias. El proceso de sobreendeudamiento rebasa el ámbito de las cajas de ahorro, tiene repercusiones muy profundas que es importante desglosar.

\section{SOBREENDEUDAMIENTO VISTO COMO UN PROCESO}

El sobreendeudamiento es un fenómeno que se registra en todo tipo de sectores sociales y económicos $\mathrm{y}$ a diferentes niveles, en torno al cual se han activado cantidad de iniciativas igualmente diversas en su contenido y amplitud. Entre ellas habrá que considerar las iniciativas globales que pretenden cancelar las deudas de los países o los acuerdos a nivel de naciones, como el Fondo Bancario de Protección al Ahorro (Fobaproa) o los rescates carreteros en México. También se han generado movimientos sociales, como el Movimiento de No Pago en Nicaragua y El Barzón en México. En la región de estudio existe una asociación llamada Vida Digna que ofrece asesoría legal a los deudores y se han emprendido acciones individuales para enfrentar las demandas y para pagar deudas mediante la recomposición de recursos familiares. Han llegado incluso a presentarse situaciones extremas como el suicidio en la India a consecuencia de tener deudas impagables. En México son cada vez más las personas de diferentes estratos sociales y económicos que tienen deudas con al menos una institución financiera o comercial. Alejandro López, investigador de la Universidad Nacional Autónoma de México (UNAM), reporta a este respecto:

A diciembre de 2011, los hogares mexicanos adeudan al sector bancario el equivalente a $14.3 \%$ del PIB, endeudamiento que ha crecido progresivamente en los últimos años, particularmente a partir del año 2000 (que representó el 8.7\%), en el cual las instituciones financieras comenzaron a expandir el crédito para consumo y vivienda, luego de estar limitado desde la crisis de 1995 (López, 2012: 18).

Lo más preocupante es que el incremento de los préstamos se asocia con el incremento de las ganancias de la banca. Este autor menciona además que las deudas:

generan $40 \%$ de las utilidades que obtienen los bancos vía intereses, comisiones, cuotas anuales entre otros cargos, utilidades que a junio de 2011 subieron $12.5 \%$ con respecto al mismo periodo del año precedente (López, 2012: 19).

El endeudamiento conlleva diversas facetas y dimensiones. En Bolivia se ha estudiado ampliamente este fenómeno que se presentó en el periodo 1999-2001. Varios autores consideran que sus causas se asocian a la crisis económica y a la gran oferta de microcréditos, así como a metodologías crediticias poco adecuadas a la situación de los usuarios (González y González-Vega, 2003; Bourns, 2005). En opinión de Alejandro López, no se pueden reducir las causas del endeudamiento a "la falta de educación financiera, y de un comportamiento irracional que rompe con los principales postulados de la teoría del consumidor" (López, 2012). En el mismo sentido el autor precisa que se trata de:

\footnotetext{
afirmaciones erróneas que omiten que dicho endeudamiento es parte esencial del proceso de financiarización de la economía capitalista, teniendo como principales protagonistas a los grandes bancos y a los inversionistas institucionales quienes lo promueven y que para las familias se convierte en una opción de subsistencia frente a la pérdida en el poder adquisitivo de los salarios (López, 2012: 20).
}

Desde esta perspectiva, no se puede reducir el endeudamiento a un compromiso no cumplido. Adrián González y Claudio González-Vega consideran que el sobreendeudamiento se refiere a: 


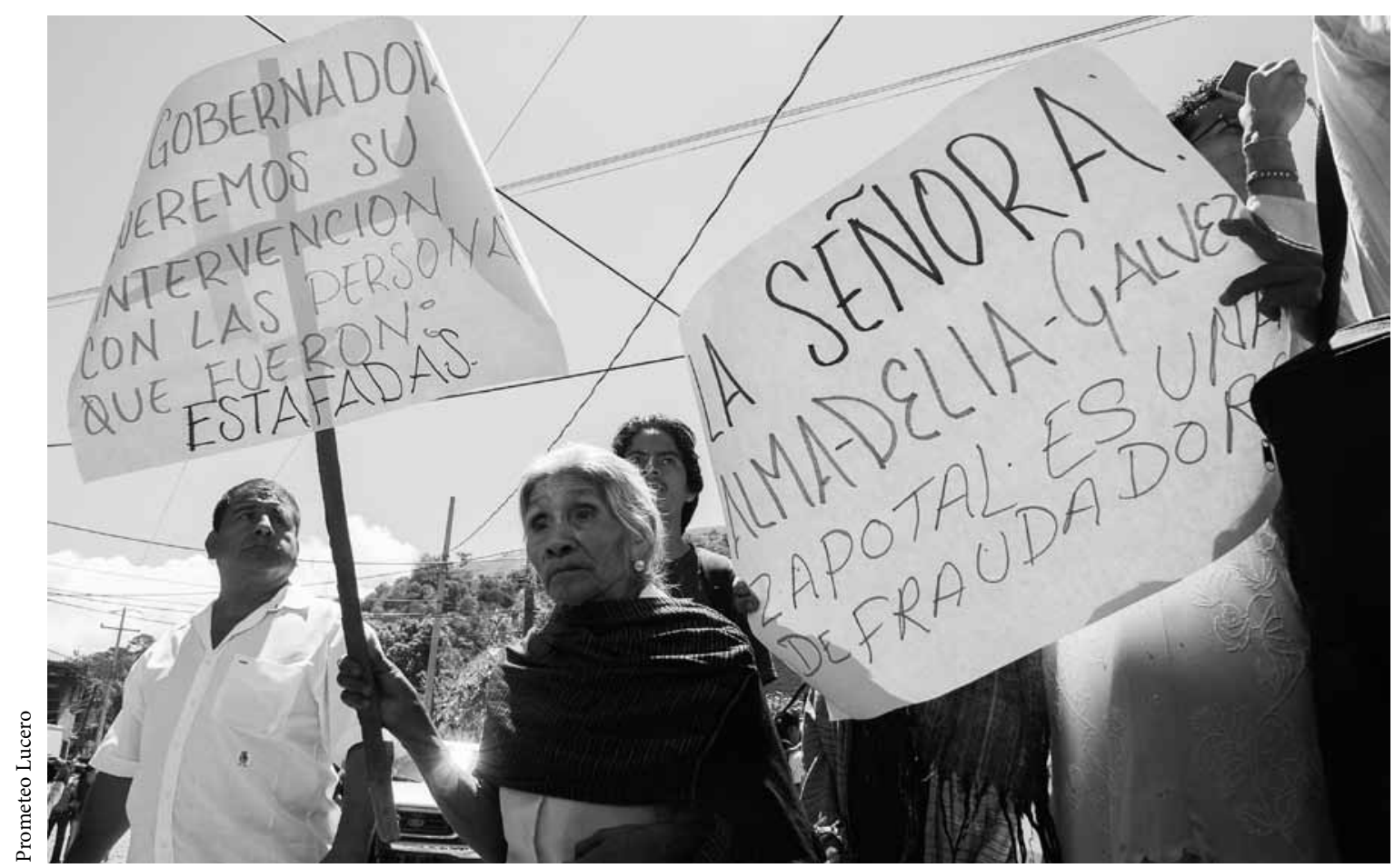

Mujeres indígenas reclaman, en un evento del exgobernador Zeferino Torreblanca en Xalpatláhuac, la intervención de las autoridades ante el fraude en una caja de ahorro en la ciudad de Tlapa, de octubre 2009.

aquellas situaciones en que el resultado final de un contrato de crédito no es el planeado (esperado) por el acreedor, el deudor, o ambos [...] diversas circunstancias pueden resultar en situaciones en las que el hogar no puede cumplir con sus obligaciones financieras a menos que realice acciones que no había planeado (extraordinarias) cuando aceptó el contrato de crédito. Estas acciones incluyen vender activos, reducir consumo, desahorrar, suspender la inversión en capital humano, trabajar más, pedir ayuda a familiares y adquirir nuevas deudas (bicicletear). Todas estas acciones tienen un costo para el hogar, reducen su bienestar y resultan en un deterioro de la demanda futura de crédito. Esto perjudica el desempeño de las organizaciones financieras (González y GonzálezVega, 2003: 13).

Estos autores aseguran que el sobreendeudamiento se presenta por alguna de las siguientes tres situaciones: la falta de voluntad de pago por parte del deudor, que éste se vea obligado a incurrir en acciones costosas para cumplir con el contrato y/o a una insuficiente capacidad de pago. Éstas están permeadas por costos que rebasan el ámbito económico-financiero, por lo que incorporo en el proceso de sobreendeudamiento a todos los actores involucrados y las relaciones que se establecen entre ellos. Así, al hablar de sobreendeudamiento habrá que contemplar diferentes ángulos: en una primera instancia la deuda, donde intervienen el deudor y el acreedor, con los matices particulares dados según la situación específica del deudor y la relación que se genera a raíz de la respuesta de ambas partes; en una segunda instancia es indispensable detectar a los actores que intervienen indirectamente y que complejizan la relación entre el deudor y el acreedor, como los familiares que ayudarán a cubrir la deuda o que se niegan a compartirla, la existencia de prestanombres, otros acreedores, cobradores y/o terceras personas afectadas; por último, las consecuencias 
que se desencadenan para cada situación tienen también repercusiones distintas tanto para cada uno de los actores mencionados como para su relación presente y futura.

\section{DINERO PARA LUCRAR, DINERO PARA SOBREVIVIR}

En cuanto a la relación entre los usuarios y los prestadores de servicios hay que precisar que éstos tienen significantes diferentes en torno al bien que los relaciona: el dinero. Desde el análisis que hace Villarreal acerca de la economía se plantea que si bien es frecuente considerarla como sinónimo de mercado, de esta forma se le "extirpa una parte importante de sus elementos constitutivos. Éstos incluyen relaciones sociales, culturales, domésticas, étnicas y políticas" (Villarreal, 2007: 19). La autora afirma que es común la idea de que el dinero:

se representa como una medida de valor estándar, pero no necesariamente funciona como tal ya que "existen distintos marcos de valoración que coexisten y se interrelacionan en el proceso de definición de equivalencias". Esto lleva a que se "descarten del análisis una gran cantidad de relaciones sociales y económicas generalmente consideradas erráticas, volátiles o subjetivas" (Villarreal, 2007: 24).

Así, para los distintos actores la representación del dinero está asociada a sus repertorios culturales. Sin embargo, se prioriza o se reconoce socialmente sólo aquellos que se circunscriben al ámbito económico, por lo que la comunicación entre actores diversos se entorpece si no se explicitan estas diferencias. Partiendo de este marco una de las dificultades en la relación entre las microfinancieras o las cajas de ahorro con las mujeres prestatarias está en los significantes que cada parte le da al dinero. Para las microfinancieras comerciales el dinero es un bien que se invierte para generar utilidades. Por tanto, el tiempo, así como las relaciones que establece con sus trabajadores y con las usuarias, se traducen en dinero. Los valores de estas instituciones están relacionados con la productividad y eficiencia que aseguren su rentabilidad. En contraparte, para las mujeres usuarias de estos servicios el dinero es un bien escaso, nada fácil de adquirir que se destina para la reproducción básica del grupo doméstico, ya sea a través de su inversión en las actividades productivas agropecuarias y comerciales o por medio de su canalización para cubrir las necesidades básicas de alimentación, vestido, educación, salud y vivienda. Es decir, el dinero es un recurso que, junto al trabajo y la infraestructura familiar, se destina a la supervivencia. Para los grupos domésticos de las mujeres usuarias el dinero no representa un valor socialmente estándar en relación con el conjunto de sus recursos: trabajo, tierra e infraestructura. El valor comercial de estos tres recursos no es equiparable a su valor en las estrategias de supervivencia de los grupos domésticos.

En lo que se refiere a las cajas de ahorro, si bien el dinero, el tiempo y las relaciones tienen también significantes diferentes respecto de los que tienen para sus socias/usuarias, estas instituciones generalmente pretenden encontrar canales de comunicación, dinámicas y relaciones de corresponsabilidad que tiendan a desarrollar capacidad para zanjar estas diferencias. En esta relación entre oferentes de crédito y solicitantes se requiere de mecanismos claros y precisos que contemplen la existencia de significantes disímiles entre ambas partes, no sólo respecto del dinero, sino del tiempo y de las formas en que establecen las relaciones con su entorno.

\section{LA VULNERABILIDAD Y LAS MUJERES RURALES}

La vulnerabilidad está asociada con la dificultad para que la población responda de manera eficaz y eficiente a las situaciones imprevistas que constantemente se presentan. Kabeer considera que la vulnerabilidad se asocia a: 
La incertidumbre básica que rodea a la capacidad de la gente pobre de cumplir sus necesidades de una manera regular y segura. La vulnerabilidad puede reflejar una exposición a riesgos idiosincráticos y de corto plazo, o puede ser resultado de factores estructurales que han estado presentes desde hace mucho tiempo. Los pobres son más vulnerables que el resto de la población porque enfrentan una mayor variedad de riesgos e impactos y tienen menos recursos en que apoyarse (Kabeer, 2012: 45).

La vulnerabilidad también se relaciona con las pocas oportunidades que tiene la población margina$\mathrm{da}$, con la fragilidad económica y con las escasas herramientas y el estrecho margen de maniobra para responder a los frecuentes imprevistos que se le presentan en el medio rural. Así, la vulnerabilidad se expresa de diversas formas y contiene muchas variables. En lo que corresponde a la dimensión educativa, se expresa en la casi nula formación financiera de la población rural y se concreta en la falta de experiencia para comprender a cabalidad

las implicaciones del compromiso que se adquiere al contratar un crédito, en los planes poco realistas que hacen muchas mujeres para pagar sus créditos y en la falta de capacitación que respalde los negocios que ellas emprenden.

Si bien la vulnerabilidad es una de las razones de la gran demanda de créditos, este fenómeno está vinculado a su vez con el origen del sobreendeudamiento, por la dificultad que implica enfrentar, económicamente, situaciones imprevistas que provocan desequilibrios en la dinámica general del grupo doméstico: enfermedades, accidentes, problemas en las actividades productivas de la familia o en los negocios que las mismas mujeres emprenden, la vulnerabilidad de la clientela de estos negocios, irregularidades en la recepción de las remesas, inestabilidad de los precios de los productos agropecuarios, cambio climático y malos cálculos en la relación ingresos-gastos, además de los problemas maritales en tanto que todavía son mayoría las mujeres que dependen económicamente de sus maridos.

\section{LA DOBLE CARA DE LAS MICROFINANCIERAS COMERCIALES}

Algunos de los elementos que utilizan las microfinancieras comerciales para asegurar su rentabilidad están asociados al sobreendeudamiento.

\section{Créditos rápidos, fáciles de pagar}

La rentabilidad en las microfinanzas descansa en lograr una cobertura a gran escala. Para ello estas instituciones masifican sus servicios: facilitan al máximo la entrega de créditos y los hacen atractivos a través de un esquema de pequeños pagos. Para asegurar la entrega rápida de los créditos, muchas de las microfinancieras comerciales no utilizan instrumentos de análisis para determinar la capacidad de pago de su clientela, por lo cual prácticamente otorgan créditos a quien los pida. Sin embargo, el riesgo que esto conlleva no lo corre la institución, sino las mujeres del grupo en cuestión porque son ellas quienes pagan las letras de sus compañeras de grupo. Los pagos se hacen en pequeños montos semanales. Estos esquemas representan una presión muy grande para la clientela, aun cuando las mujeres cuenten con un negocio: una semana es un plazo muy corto para que el crédito invertido en un negocio genere su propio pago. Es común que los días de pago de crédito de Compartamos varias mujeres busquen entre sus conocidas apoyos para solventar sus letras. Hay mujeres que incluso planean sus actividades para no estar ese día en la comunidad y no verse en la necesidad de negarse a prestar a sus familiares y amigas: "Los miércoles es el día de pago de Compartamos, ese día yo nunca estoy en el pueblo".

\section{La "solidaridad" como estrategia para la rentabilidad}

Las microfinancieras comerciales trabajan con grupos solidarios e instituyen la "solidaridad" como un mecanismo vinculado con su rentabilidad, ya que 
trasladan a su clientela los gastos de cobranza y riesgos intrínsecos de la actividad microfinanciera. Todos los movimientos se hacen en los grupos, a los trabajadores de las microfinancieras les corresponde asegurar que los pagos de todas las clientas estén completos y llegan a pasar por encima de la dignidad de la gente:

Cuando viene la promotora los lunes ya tiene que estar el pago de todas. Lo junta la tesorera del grupo, si falta un pago, lo tenemos que poner entre todas. Como es solidario... Una vez [la promotora] no nos dejó salir de casa de doña Lola hasta tener completo el pago de todas. Como faltaba una, no pudimos salir y nadie traía más dinero. Ahí vimos pasar a mi sobrino y le dijimos que nos mande dinero. Así cerramos la bolsa y nos dejó salir la promotora (entrevista a Alicia, 2010).

Las integrantes del grupo son quienes cubren las letras no pagadas por sus compañeras. Cada semana llevan al banco el pago de todas para depositarlo. Los grupos asumen estos costos de transacción: el pasaje, el riesgo de llevar el efectivo al banco y el jornal del día de quien va a depositar. A través de este mecanismo "solidario", las microfinancieras comerciales transfieren a la clientela los gastos de cobranza, el costo de la cartera vencida y el riesgo que implica el traslado del dinero de la comunidad a la institución bancaria.

\section{Es más importante la oportunidad del crédito que su precio}

El monto de la tasa de interés de los préstamos no es regulado por la autoridad financiera a pesar de ser una de las variables que inciden en el tipo de impacto de la actividad microfinanciera sobre los usuarios. Este vacío legal está respaldado por varios autores: hay quienes plantean que para garantizar la permanencia de los servicios financieros a los pobres las tasas de interés deben cubrir todos "los costos de operación [de las instituciones microfinancieras], incluyendo las reservas por pérdida de préstamos; el costo de los fondos y la inflación" y asegurar una ganancia (Rhyne y Otero, 1998: 53). Robinson discute la pertinencia de cobrar tasas altas de interés con base en dos premisas: 1) para los empresarios pobres, el acceso al financiamiento tiende a ser un tema mucho más importante que el costo del mismo (tasa de interés), y 2) los costos de las instituciones microfinancieras son mayores a los de las instituciones bancarias, por lo que tienen que cobrar tasas de interés mayores. La propuesta de esta autora es que el beneficio hacia los pobres radica en asegurar los servicios financieros de buena calidad, permanentes y a gran escala mediante la creación de instituciones microfinancieras sólidas y sostenibles, aunque ello implique cobrar altas tasas de interés (Robinson, 2004: 31). Esta anuencia de la autoridad financiera y de los teóricos de las microfinanzas comerciales respalda el alto costo de los servicios financieros, donde el costo anual total (СAT) llega a superar el $100 \%$.

\section{¿CÓMO VIVE LA POBLACIÓN EL SOBREENDEUDAMIENTO?}

Para la población el endeudamiento tiene costos que rebasan el pago de la deuda y los moratorios correspondientes. Observamos tres tipos de costos: económicos, sociales y personales.

\section{Costos económicos}

Los costos económicos del sobreendeudamiento no se refieren sólo al sobreprecio o al interés moratorio que los deudores tendrán que cubrir por el retraso en el pago. Es común que, como parte de este proceso o con el fin de salir de esta situación, haya pérdidas económicas relacionadas con el patrimonio o con las fuentes de ingreso, cuyas consecuencias afectan negativamente el futuro del grupo doméstico. A continuación se expone una gama de situaciones. 


\section{Pérdida del patrimonio}

Cuando una deuda se incrementa y los deudores no tienen forma de pagarla, es frecuente que recurran al pago en especie o a la venta de bienes materiales. El ganado vacuno y los terrenos son los bienes que suelen utilizarse para pagar las deudas. Hay ocasiones en las que estos bienes tienen un valor comercial relativamente bajo y el ingreso obtenido por su venta no compensa el valor y la utilidad que éstos representan para el grupo doméstico. Si bien se resuelve un problema al utilizar la venta de los medios de producción o de parte del patrimonio para cumplir con un contrato de crédito no pagado, se desencadenan por otra parte serias dificultades que afectarán el futuro de la dinámica económica del grupo doméstico.

Un caso ilustrativo es el de Rosa, quien tiene un serio retraso en el pago de su crédito debido a un embarazo de alto riesgo y por prescripción médica tuvo que dejar su negocio de venta de antojitos. Asociado a este problema de salud, está la negativa gasté el dinero" Rosa se vio obligada a vender su gasté el dinero". Rosa se vio obligada a vender su puesto ambulante de preparación de comida, que incluye la mesa de cocina-quemadores y dos juegos de mesas con sus respectivas sillas. Aunque Rosa pagó su deuda, ahora queda un vacío para su futuro. En estas situaciones se hacen evidentes los significantes que tiene el dinero, ya que los recursos en disputa significan para la microfinanciera recuperar su inversión y su ganancia, mientras que para la deudora representan la imposibilidad de mantener la fuente de ingreso para su supervivencia.

\section{La deuda se comió el negocio}

Muchas socias de la caja de ahorro han logrado instalar un negocio estable para generar su propio ingreso. Uno de los elementos de éxito está en manejar de manera diferenciada los recursos para la supervivencia diaria y los del negocio y en conocer su

dinámica para ubicar los momentos para disponer de los ingresos o inyectar recursos (Guzmán, 2010). Varios casos de sobreendeudamiento y de pérdida total del negocio tienen su origen en la forma de utilizar el crédito. Ramona, por ejemplo, reflexiona sobre este aspecto:

Hace cuatro años puse mi papelería, pequeñita, pero de ahí hemos sobrevivido mis dos hijos y yo. Desgraciadamente un negocio necesita que le invierta uno, y cuando tengo le invierto, pero desgraciadamente de ahí [del dinero que era para invertir en la papelería] tomo para comer, no tengo de otro lado de dónde agarrar, y lo que pedí [préstamo] me lo como [...] si pudiera retrasar el tiempo no cometería el mismo error, fue un error, de momento la saca a una de apuros, pero después, hay que pagarlo (entrevista a Ramona, 2008).

Cada vez son más frecuentes los casos como el de Ramona, ya que muchas mujeres sobreestiman el crédito y lo utilizan como herramienta de pago de deudas o para el consumo. Asimismo, es común encontrar que quienes obtuvieron varios créditos simultáneos suelen tener problemas de pagos con más de una institución financiera. Muchos de los costos económicos asociados al proceso de sobreendeudamiento están relacionados con la falta de acompañamiento y asesoría técnica para la planeación y el desarrollo de los negocios.

\section{Costos personales}

\section{Las deudas cambian la vida}

A pesar de que la práctica de solicitar préstamos es muy frecuente, muchas mujeres viven un cierto grado de tensión mientras solventan la deuda, aun cuando estén cubriendo puntualmente sus pagos. Un ejemplo es Juana, quien cada vez que hace un pago de letra hace referencia al número de letras que le quedan por pagar y al liquidar sus créditos expresa su alivio con un suspiro: “iya terminé!”. Esta 
tensión es entendible por la incertidumbre que vive la población. Hay quienes padecen serios problemas de salud por la tensión. Crista está construyendo cuartos para que la renta sea su "jubilación":

Por eso le digo que yo no puedo ser libre para irme a pasear, porque tengo que trabajar. $\mathrm{Al}$ año son tres créditos, pero son 25120 pesos de cuatro meses, más 3120 pesos de interés al ciclo, son 10000 al año que estoy regalando $[\ldots]$ es mucho interés $[\ldots]$ ya me duele la espalda y no camino bien [...] ya estoy cansada (entrevista a Crista, 2009).

Una manera que aparenta disminuir las tensiones de la deuda es solicitar un segundo préstamo para cubrir el primero, lo que crea una espiral de la que es muy difícil salir. Ramona lo ha hecho repetidas veces:

Un préstamo la lleva a otro y a otro, usa uno para tapar a otro. Yo les digo que no cometan el error de pedir en otro lado y tratar de tapar el hoyo con ese dinero, porque después el préstamo ése lo llevan a otro préstamo y a otro. Llega un momento que ya no tenemos de dónde pagar (entrevista a Ramona, 2008).

Algunas mujeres deciden simplemente no pagar su deuda, para lo cual han desarrollado diversos tipos de prácticas. Hay quienes nunca se niegan a pagar pero no hacen esfuerzos para abonar a su deuda, otras dejan de frecuentar los lugares donde haya riesgo de que se les cobre o se esconden para no recibir presiones. Ante la presión y la tensión algunas mujeres han llegado a vivir situaciones nunca contempladas relacionadas con conflictos maritales, con familiares o con el vecindario que, por una parte, implican abuso de confianza y, por otra, las someten a la autohumillación, que es difícil de superar y que a futuro tiene consecuencias de exclusión social. Uno de estos casos es el de Tristana: su problema se presentó cuando su marido regresó de Estados Unidos y se enfrentó al desempleo y al salario en pesos mexicanos. No fue fácil para ella restringir el nivel de consumo al que estuvo acostumbrada ni para su esposo

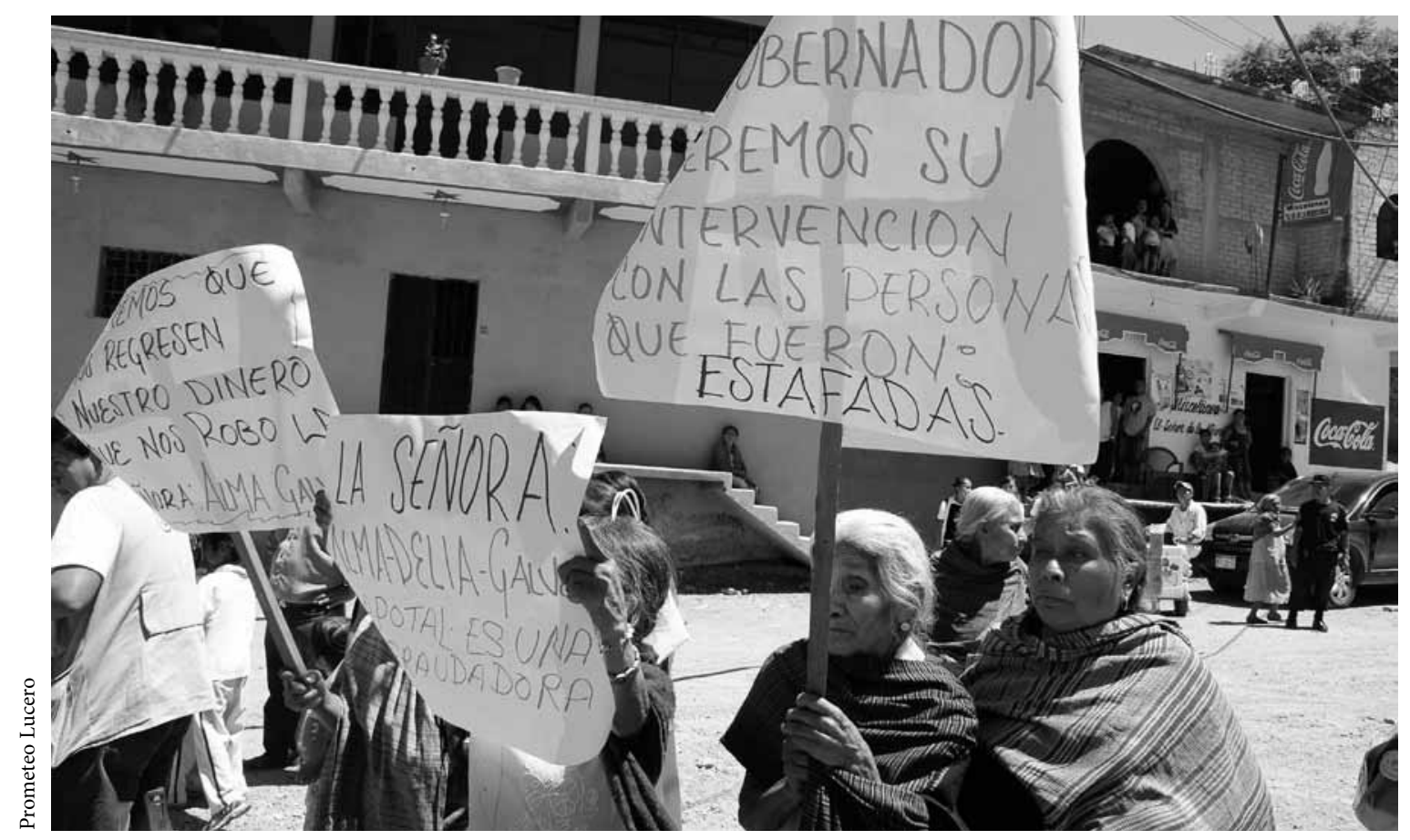

Mujeres indígenas defraudadas en una caja de ahorro exigen que se atienda su caso, Tlapa, octubre de 2009. 
aceptar trabajos pagados bajo el régimen y la moneda mexicana. Como Tristana era promotora, tomó el dinero de los pagos de su grupo e informó: "lo tomé porque lo necesitaba”. Para el grupo, su comunidad y la caja de ahorro fue una gran sorpresa. Si bien al principio fue muy difícil para ella afrontar su "falta”, con el tiempo ha asimilado la situación, de manera que sin negarse a pagar incumple los acuerdos derivados de negociaciones y sigue solicitando créditos a microfinancieras comerciales para completar su supervivencia. Incluso, se burla de sus vecinas que sí pagan puntualmente sus préstamos. Esta actitud ha indignado a sus compañeras de grupo y la han aislado.

Las consecuencias más graves son aquellas en las que la violencia permea las relaciones. En esos casos es frecuente que las mujeres no informen a sus maridos de muchas de sus actividades y decisiones, solicitan créditos y los pagan de sus propios ingresos o del dinero que reciben para los gastos familiares y que logran ahorrar para cubrir sus compromisos

financieros. Sin embargo, en ocasiones sus cuentas y sus planes no llegan a feliz término. Una de las preocupaciones de las deudoras es que el marido se entere de sus deudas, porque se desencadenarían reacciones violentas. Las microfinancieras comerciales aprovechan estas circunstancias como presión para que la clientela pague. En contraste, uno de los retos de la cobranza para las cajas de ahorro está en cómo manejar estos casos, cuándo y cómo involucrar a los maridos en este proceso para que la deudora no salga perjudicada, pero tampoco la caja de ahorro ni sus socias.

\section{Costos sociales}

Los programas microfinancieros, sociales o comerciales, se sostienen en dos pilares: la palabra de las mujeres y los vínculos sociales de los dominios familiar y comunitario. La primera se destaca por la coherencia entre lo que las mujeres dicen y lo que hacen, mientras que los segundos son las relaciones que "cobijan" a la población y representan la garantía moral que respalda a las prestatarias. Muchas cajas de ahorros pretenden fortalecer estos pilares a través de los procesos organizativos que impulsan y de los proyectos no financieros que promueven. En cambio, las entidades comerciales y lucrativas frecuentemente hacen uso de estos pilares para disminuir sus gastos y sus riesgos. El sobreendeudamiento está agrietando y deteriorando tanto la palabra de las mujeres como los vínculos sociales de las comunidades. Las repercusiones de este proceso son parte de los costos personales y sociales del proceso de sobreendeudamiento.

\section{Relaciones sociales agrietadas}

Los vínculos sociales suelen agrietarse por el uso de prestanombres para acceder a altos montos de crédito. Esta práctica se lleva a cabo con muchas inconsistencias, ya que por un lado se realiza de manera clandestina, sin que el grupo ni la promotora lo sepan, y por otro lado generalmente se hacen acuerdos y compromisos verbales entre las prestatarias, sin especificar las responsabilidades que cada parte asumirá ante los escenarios que se presenten. Algunas personas prometen una parte del crédito para quien prestó el nombre, pero no queda claro quién pagará los intereses correspondientes de esta “porción” del crédito.

Un caso difícil fue el de Marilí, quien para ampliar su casa solicitó a una caja de ahorro cuatro créditos simultáneos a través de ella, su madre, su suegra y una amiga. Ella tenía pensado pagar toda su deuda con las remesas que le enviaba su esposo de Estados Unidos, pero el dinero no llegó. Ante la falta de pago, la caja de ahorro inició la presión hacia las cuatro socias. La primera dificultad estribó en aclarar quién era la verdadera deudora y cuál era la dimensión de la deuda. Sólo Marilí tenía la información completa y sus "prestanombres" fueron muy discretas y soportaron la presión durante varios meses. Al aclarar la situación, las demás compañeras del 
grupo se sintieron engañadas y perjudicadas por los retrasos en los pagos, aunque prefirieron no manifestar su enojo por las consecuencias que ello traería al vecindario. Es frecuente que los problemas del endeudamiento trasciendan a la deudora y a sus prestanombres y afecten también a las integrantes de los grupos, ya que en las microfinancieras comerciales el grupo está obligado a pagar la deuda de las morosas y en las cajas de ahorro se suspenden los créditos a todas las integrantes ante la falta de pago.

\section{La deuda en cadena, la deuda estratégica}

En el caso de los grupos domésticos cafetaleros muchos de los créditos solicitados entre abril y septiembre se destinaron a la supervivencia porque durante ese periodo no hubo ingresos. Planean pagar estos créditos en la temporada de cosecha de café. Sin embargo, no siempre hay posibilidades de empatar los pagos de los créditos con los ingresos provenientes de las cosechas, lo cual trae consecuencias diversas. El caso de la familia Espino ilustra este hecho. En 2009, la familia tuvo un serio problema y decidió no cubrir la deuda que tenían las dos hijas y la madre con la caja de ahorro sino hasta que iniciara la cosecha de café y que éste tuviera un buen precio. Esta decisión de no pago fue una estrategia de la familia para no malbaratar la cosecha y no perder parte de su patrimonio, aun cuando afectara no sólo a su grupo, sino a la caja de ahorro en su conjunto. Algunas socias, por "imitación", también relajaron sus pagos, lo que aumentó la cartera vencida de esta comunidad y, por tanto, tuvo un serio impacto en el resto de las socias de la caja. Las socias cumplidoras de otras comunidades mostraron su preocupación por la seguridad de sus ahorros. La caja de ahorro tuvo que diseñar una estrategia de información pormenorizada sobre los fondos y las reservas financieras que protegían los ahorros de las socias, mientras paralelamente se analizaba de manera colectiva en la comunidad deudora la situación de cada grupo doméstico y la forma de recuperar los pagos atrasados.

\section{AMORTIGUAR PRESIONES: LAS REDES SOCIALES}

Los vínculos sociales son un sostén de las comunidades rurales y les permiten resistir como individuos, familias y colectividades ante la crisis económica, ecológica y social que las invade. Sin embargo, los hechos que acabamos de presentar ilustran cómo el sobreendeudamiento tiende a quebrantarlos. También está la otra cara de la moneda: muchas mujeres han logrado liquidar sus deudas gracias a estos vínculos con familiares, vecinos u organizaciones. Crista obtuvo un préstamo de su hermano. Para salir de deudas con diferentes microfinancieras y cajas de ahorro, Flora puso a la venta el terreno que le había asignado su padre para que viviera, tardó varios meses en venderlo porque no encontraba al comprador ideal, no quería malbaratarlo, como le sucedió a su hermana Sandra, quien vendió su casa a un precio muy bajo por la presión de las microfinancieras. Mientras juntaba el dinero, tuvo que salir de su comunidad para que no la encontraran los acreedores. Finalmente, su cuñada compró el terreno para que los hijos de Flora no perdieran su patrimonio.

Si bien la comunidad representa una presión para quienes incumplen las normas sociales y son señalados, hay también una faceta en la cual las redes sociales facilitan la vida de estas personas. En el caso de las deudoras, se presenta esta dualidad a través de enojo, rechazo e indignación por las actitudes y faltas, al mismo tiempo que se les apoya para amortiguar las consecuencias. A Bertha, por ejemplo, a pesar de ser del conocimiento público el nivel de deudas que tiene con varias instituciones, incluso en las tiendas de la comunidad, varias tenderas le siguen fiando porque no pueden negarle la comida "por sus hijos", aun cuando saben que estos préstamos tampoco serán pagados. A través de las redes sociales, la misma población pone límites a la presión que se 


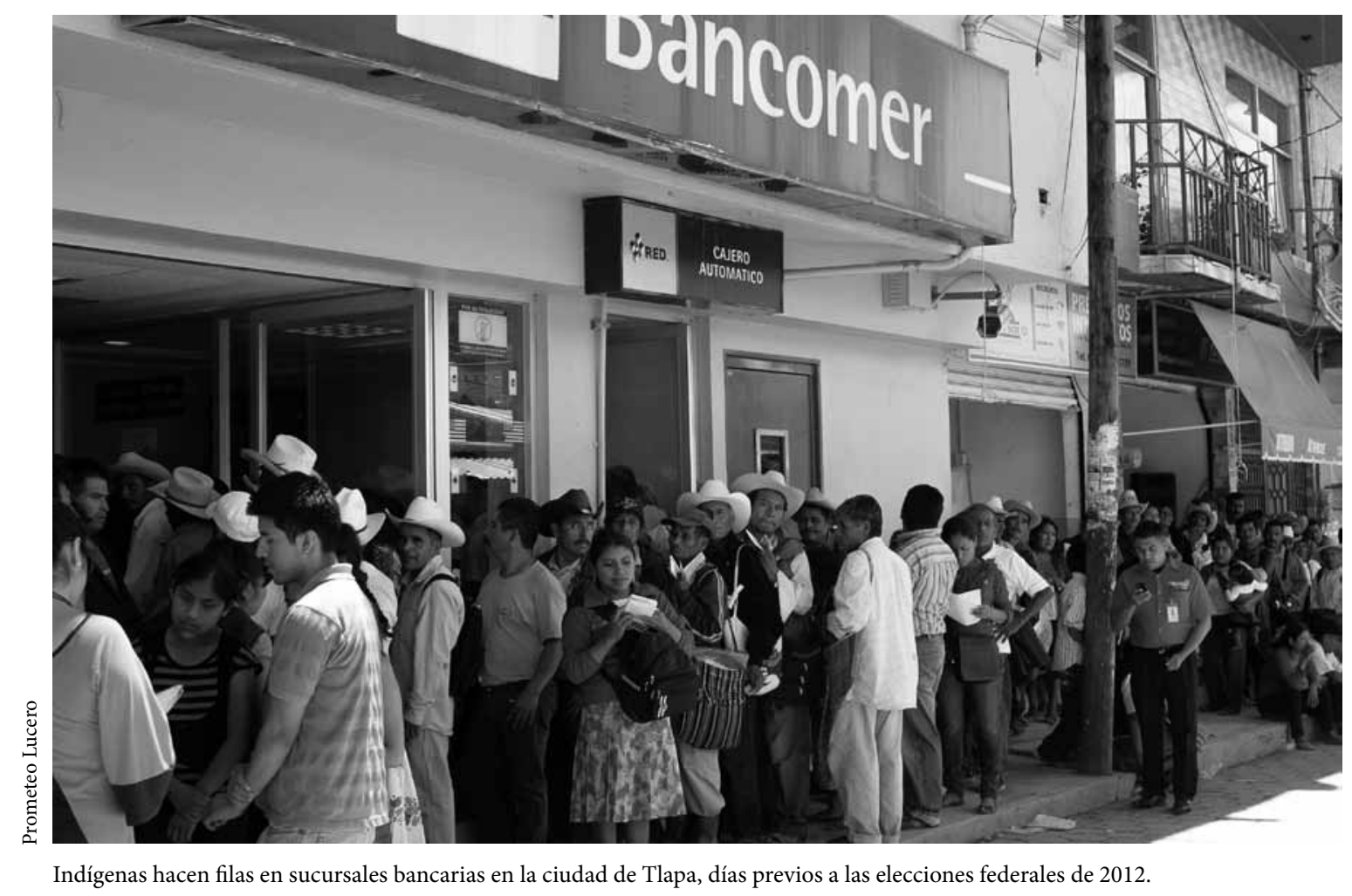

ejerce sobre las deudoras. Hay acciones que la misma población no está dispuesta a realizar por respeto a la integridad de las deudoras: hay comunidades donde se han negado a vocear por el sonido a las deudoras y tampoco han aceptado hacer visitas de todo el grupo a personas deudoras que tienen enfermedades relacionadas con tensiones o que viven con personas enfermas. Lo han expresado de esta manera:

No, mejor no vamos a ver a Elsa, ahí vive su mamá y tiene azúcar, no se vaya a poner mal (por la impresión) [...] Ustedes vienen hoy, van con las deudoras y se van, nosotras nos quedamos aquí y las vemos diario (entrevista a Adela, 2010).

Algunas cajas de ahorro han logrado formar parte de las redes sociales en las comunidades. A pesar de que los vínculos no son tan fuertes como los familiares o vecinales, se han establecido lazos a partir de la comunicación, el intercambio y la confianza generada por las diversas actividades que realizan. Estas instituciones no pueden pasar por alto las deudas de sus socias porque no son instituciones de beneficencia y los créditos no pagados estarían perjudicando el ahorro de sus compañeras, pero establecen mecanismos para evitar el sobreendeudamiento.

\section{CONCLUSIONES}

El proceso de sobreendeudamiento en el medio rural es causado por diversos factores, entre los que se encuentran elementos estructurales asociados al sistema económico que se expresan en la falta de oportunidades de la población para acceder a fuentes de ingreso con una remuneración justa, ya sean trabajos asalariados, precios justos para los productos agropecuarios o condiciones para impulsar un 
micronegocio, por lo que a menudo se presentan situaciones imprevistas difíciles de sortear. Por otra parte, la educación a la población se proporciona de manera fragmentada y no contempla capacitación empresarial para acompañar a las mujeres en sus negocios o educación financiera para hacer un uso óptimo de los diversos servicios financieros que se ofrecen en la región.

Para muchas mujeres los créditos representan una esperanza para salir de situaciones difíciles y los utilizan como una estrategia de supervivencia, no como un recurso financiero. La función de los créditos es generar patrimonio: deben invertirse en acciones, actividades productivas, bienes o medios de producción. Sin embargo, se destinan para el consumo que no logra cubrirse con los ingresos cotidianos. Este fenómeno es muy riesgoso porque los créditos no quedan respaldados para asegurar el pago en tiempo y forma y la población se está descapitalizando por la cantidad de intereses que pagan por este servicio. La gran demanda de créditos y la aceptación de condiciones que pueden atentar en contra del mismo usuario denotan las limitaciones económicas de la población, la necesidad de contar con recursos externos y el vacío de políticas públicas destinadas a estos sectores. Asimismo, ponen en evidencia la falta de servicios financieros adecuados para cubrir las necesidades de la población.

Dentro del ámbito cultural, el proceso de sobreendeudamiento está asociado a que el dinero tiene significantes distintos para las mujeres, para las microfinancieras comerciales y para las cajas de ahorro, y cada actor tiene formas diferentes para acceder a este recurso. En este sentido, no se puede hablar de relaciones equitativas entre las microfinancieras comerciales y su clientela, ya que para estas instituciones el dinero, la infraestructura, el tiempo y las relaciones están permeadas por la rentabilidad y las ganancias, mientras que para las mujeres rurales estos recursos representan su supervivencia. En las cajas de ahorro si bien se presentan contradicciones con sus socias por la forma en que se concibe y se usa el dinero, las discordancias pretenden disminuirse a través de negociaciones dialogadas.

El proceso de sobreendeudamiento está relacionado también con la vulnerabilidad de la población y con situaciones imprevistas que surgen cotidianamente en los grupos domésticos rurales, ante las cuales un amplio sector tiene poca capacidad de maniobra en tanto que no cuenta con el suficiente respaldo económico y social para hacerles frente. Las microfinancieras comerciales disponen del dinero sin restricciones y son las que definen las reglas de la relación con su clientela. Así, las facilidades de acceso a los créditos y los pequeños montos para el pago de los préstamos representan un mecanismo de mercadotecnia. Estas facilidades y la transferencia que las microfinancieras hacen a su clientela tanto del pago de la morosidad como del costo del traslado de los recursos aseguran la rentabilidad de estas instituciones.

Las microfinancieras comerciales generan sustantivas ganancias a costa de la población más vulnerable sin ningún control de la autoridad financiera del país, lo que genera un proceso creciente de sobreendeudamiento en los usuarios de estos servicios. El proceso de sobreendeudamiento tiene costos personales y económicos para los involucrados en la deuda, que muchas veces perduran una vez pagada la misma. Las redes sociales juegan un papel importante para amortiguar las consecuencias del proceso de sobreendeudamiento, toda vez que ayudan a disminuir la presión de las microfinancieras y a generar condiciones para que las deudoras resuelvan sus compromisos financieros. Sin embargo, este fenómeno también deteriora los vínculos sociales cimentados por la identidad y la confianza, elementos que son transgredidos por la manera en que algunos individuos manejan sus costos o por la forma en que las instituciones involucran a estas redes. Este tipo de conflictos son nuevos, por lo que convendría analizar el grado en que se minan las redes sociales o bien la capacidad que tiene la población para reforzar sus vínculos sociales y recomponer las relaciones agrietadas por los conflictos ocasionados por el proceso de sobreendeudamiento. 
Una de las posibilidades de frenar el proceso de endeudamiento radica en la voluntad política del Estado para establecer políticas públicas que pongan un alto a la voracidad de las microfinancieras y aseguren educación financiera para que la población tenga la capacidad de elegir el servicio financiero que realmente necesita. Asimismo se requiere garantizar que los usuarios de servicios financieros tengan acceso a capacitación, asistencia técnica y acompañamiento cuando invierten los créditos y sus ahorros en actividades económicas productivas, transacciones mercantiles o construcción de vivienda, incluyendo la comercialización de los productos. Por otro lado, se requieren políticas públicas que detengan la descapitalización del medio rural y se enfoquen en generar empleos, promover empresas sociales, revitalizar la producción y estimular, proteger y encauzar el mercado de productos campesinos.

\section{BIBLIOGRAFÍA}

Bourns, Nathanael, 2005, Sobreendeudamiento en las microfinanzas salvadoreñas. ¿Existe algún problema?, Programa de Fortalecimiento de las Microfinanzas Rurales, United States Agency for International Development, San Salvador.

Castillo, Alfonso, 2012, "Ahorro, vulnerabilidad y estrategias de desarrollo. Un caso en México", en Revista de Microfinanzas y Banca Social, vol. 2, Fundación Cajamar, España, pp. 223-249.

Cumbre de Microcrédito, 2013, "Alianza contra la Pobreza: Finanzas, Gobierno, Empresas y Sociedad Civil", 9-11 de octubre, Centro Internacional de Convenciones de Filipinas, Consejo de Microfinanzas de Filipinas, Filipinas.

Dichter, Thomas, 2007, "Una segunda mirada a las microfinanzas: la secuencia de crédito y crecimiento en la historia económica”, en línea: <http://www.elcato.org/ pdf_files/ens-2007-03-27.pdf $>$.

González, Adrián y Claudio González-Vega, 2003, Sobreendeudamiento en las microfinanzas bolivianas, 1997-2001, Rural Finance Program, The Ohio State University, Ohio.
Guzmán, Gabriela, 2009, “Desempeño Social en Colmena Milenaria”, en Panal de Ideas, núm. 41, pp. 10-16. ,2010, "Aprendizajes y estrategias de las socias de Comucafi para la conformación de sus pequeños negocios", ponencia, $70^{\circ}$ Congreso Anual de la Sociedad de Antropología Aplicada, Society for Applied Anthropology, Mérida.

Kabeer, Naila, 2012, “ ¿Son las microfinanzas una varita mágica para el empoderamiento de las mujeres? Un análisis de hallazgos en el sur de Asia”, en Magdalena Villarreal y Lourdes Angulo (coords.), Las microfinanzas en los intersticios del desarrollo. Cálculos, normatividades y malabarismos, Fondo Jalisco de Fomento Empresarial, Universidad Pedagógica Nacional, Centro de Investigaciones y Estudios Superiores en Antropología Social, México, pp. 43-68.

López, Alejandro, 2012, "El endeudamiento de los hogares en México", en Boletín Momento Económico, año 2, núms. 15-18, Nueva Época, pp. 17-21, en línea: <http:// www.iiec.unam.mx/academicos/alejandro-l-pez $>$.

Lorío, Alina, 2009, "Movimiento de No Pago", en El Observador Económico, en línea: <http://www.elobservadoreconomico.com/articulo/933>.

MFI Solutions, 2008, "La comercialización de las microfinanzas y su futuro. La opI de Compartamos. Debates y Aprendizajes", MFi Solutions, La Colmena Milenaria, México.

Rajshekhar, M., 2010, “Microfinance: What's Wrong with It", en The Economic Time, en línea: <http://economictimes.indiatimes.com $>$.

Rhyne, Elizabeth y María Otero, 1998, "Servicios financieros para microempresas: principios e instituciones", en María Otero y Elizabeth Rhyne (comps.), El nuevo mundo de las finanzas microempresariales. Estructuración de instituciones financieras sanas para los pobres, Plaza y Valdés, Saldebas, México, pp. 43-60.

Robinson, Marguerite, 2004, La revolución microfinanciera. Finanzas sostenibles para los pobres, Secretaría de Agricultura, Ganadería, Desarrollo Rural, Pesca y Alimentación, Banco Mundial, Inca Rural, México.

Rutherford, Stuart, 2008, Los pobres y su dinero, Colmena Milenaria, Universidad Iberoamericana, México.

Villarreal, Magdalena, 2007, "La economía desde una perspectiva de género: de omisiones, inexactitudes y preguntas sin responder en el análisis de la pobreza”, en La Ventana. Revista de Estudios de Género, vol. II, núm. 25, Universidad de Guadalajara, Guadalajara, pp. 7-42. 